https://doi.org/10.30910/turkjans.679898

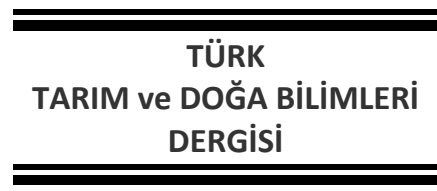

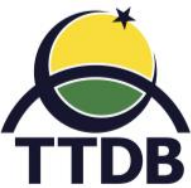

www.dergipark.gov.tr/turkjans

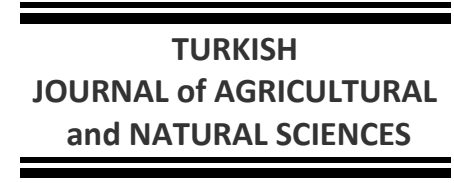

Araştırma Makalesi

\title{
Yarı Kurak Koşullarda Ekim Zamanlarının Çörekotu (Nigella sativa L.) Verim ve Verim Özelliklerine Etkisi
}

\author{
Memet INAN*
}

Adıyaman Üniversitesi Tarım Bilimleri ve Teknolojileri Fakültesi, 02400 Kâhta /Adıyaman

*Sorumlu yazar: memetinan@gmail.com

Geliş Tarihi: 19.06.2019

Düzeltme Geliş Tarihi: 15.10.2019

Kabul Tarihi: 07.11.2019

Özet

Ranunculaceae familyasına bağlı çörekotu (Nigella sativa L.) çok önemli bir baharat ve tıbbi bitkidir. Bitkinin yarı kurak koşullarda, ekim zamanlarına bağlı olarak tohum verimini belirlemek amacıyla 4 farklı zamanda (kasım, aralık, ocak ve şubat) tohum ekimleri yapılmıştır. Bu amaçla, deneme 2015- 2016 ve 2016 2017 yetiştirme sezonlarında Adıyaman Üniversitesi Kahta MYO uygulama alanında, tesadüf bloklarında 3 tekrarlamalı olarak yürütülmüştür. Çalışmada Çameli çörekotu çeşidinin tohumları materyal olarak kullanılmıştır. Bitkilerin su ihtiyacı yağışla karşılanmış, sulama yapılmamıştır. Denemede çeşide ait bitki boyu (24.13- $44.93 \mathrm{~cm})$, dal sayısı (2.67-5.30 adet/bitki), kapsül sayısı (6.08- 11.47 adet bitki ${ }^{-1}$ ), kapsüldeki tohum sayısı (51.97- 66.13 adet kapsül ${ }^{-1}$ ), bin tohum ağırlığı $(2.50-2.64 \mathrm{~g})$ ve tohum verimleri (31.49- $\left.49.11 \mathrm{~kg} / \mathrm{da}\right)$ belirlenmiştir. Ekim zamanına bağlı olarak, ekimin gecikmesiyle birlikte, incelenen tüm özelliklerde azalmaların olduğu saptanmıştır. Bu nedenle yarı kurak koşullarda, sulama imkânının olmadığı durumlarda, sonbahar ilk yağışlarından hemen sonra ekimlerin, kasım ayı içerisinde yapılması gerektiği sonucuna varılmıştır.

Anahtar kelimeler: Çörekotu, ekim zamanı, Nigella sativa, yarı kurak koşullar.

\section{Effect of Sowing Dates on Yield and Yield Characteristics Black Cumin (Nigella sativa L.) in Semi-Arid Conditions}

\begin{abstract}
Seeds have been sown at 4 different times (Nowember, December, January and February) to determine the seed yield of plant in semi-arid conditions. For this purpose, the experiment has been carried out with 3 replications according to randomized block experiment design in Adiyaman University Kahta Vocational School Research and Application area in 2015- 2016 and 2016- 2017 yield seasons. In this study, seeds of Çameli black cumin seed have been used as a material. Water needs of plants have been met with precipitation, irrigation has not been done. In the experiment, plant height $(24.13-44.93 \mathrm{~cm})$, number of branches $(2.67-5.30$ number/plant), number of capsules (6.08- 11.47 number/plant), number of seed per capsule (51.97- 66.13 number/capsule), thousand seeds weight (2.50- $2.66 \mathrm{~g})$ and seed yields (31.49- $49.11 \mathrm{~kg} / \mathrm{da})$ have been determined. Depending on the time of sowing, with the delay of sowing, there is decrease in all characteristics having been examined. Therefore, in semi-arid conditions, where irrigation is not possible, it is concluded that sowing should be carried out in November immediately after the first rainfall.
\end{abstract}

Key words: Black cumin, sowing time, Nigella sativa, semi-arid conditions.

Giriş

Çörekotu (Nigella sativa L.) Ranunculaceae familyasından değerli bir ilaç ve baharat bitkisidir. Doğu Akdeniz, Güney Avrupa veya Ön Asya kökenlidir (Baydar, 2013). Bitki tohumlarının ve tohumlardan elde edilen ekstraktların soğuk algınlığını ve oksidayonu önleyici, kan basıncını düşürücü, iltihap kurutucu, mikrop ve tümör öldürücü, süt arttırıcı, sinek kovucu ve diyabete karşı kullanıldığı bildirilmektedir (Siddiqui and 
Sharma, 1996; D’Antuono ve ark., 2002; Tembhurne ve ark., 2014).

Bitkisel üretimde verim ve kaliteli tohum üretimi açısından ekim zamanı büyük önem taşımaktadır. Farklı bitkilerle yapılan çalışmalarda, ekim zamanının gecikmesiyle birlikte bitkilerin erken olgunlaşmaya çalıştığı, erken çiçek oluşumuyla birlikte erken döllenmenin olduğu, daha küçük şemsiyelerin oluştuğu, bu şemsiyelerdeki tohum sayısının azaldığı ve buna bağlı olarak verimin düştüğü bildirilmektedir (Kaleem ve ark., 2011; Moosavi, 2014; Sharangi ve Roychowdhury, 2014). Özel ve ark. (2002) $N$. sativa ve $N$. damascena türleri ile Şanlıurfa koşullarında yaptıkları çalışmada her iki tür içinde kasım ayı ortalarında ekimlerin yapılması gerektiğini ve bu ay içerisinde yapılan ekimlerden yüksek oranda tohum verimi (35.86-40.62 kg/da) alındığını saptamışlardır. Benzer ekolojik koşullarda yapılan bir çalışmada da kasım ayında yapılan ekimlerin (103.7-126.5 kg/da), şubat ayında yapılan ekimlerinden (62.9-69.2 kg/da) yaklaşık iki kat daha fazla tohum verimi alındığı bildirilmektedir (Kızıl ve ark., 2008). Mısır koşullarında çörekotu ekim zamanının ekim ayından, kasım ayına sarkması durumunda, incelenen tüm özelliklerde azalmaların olduğu bunun da tohum verimini olumsuz etkilediği tespit edilmiştir (El-Mekawy, 2012). Haq ve ark. (2015) Bangladeş'te çörekotunda ekim zamanın ekim ayından, aralık ayına sarkmasıyla kapsül sayısının, kapsüldeki tohum sayısının, bin tane ağılığının ve bunlara bağlı olarak tohum verimlerinin önemli ölçüde azaldığını saptamışlardır. Aydın ekolojik koşullarında Kılıç ve Arabacı (2016) tarafından yürütülen çalışmada tohum verimi $(80.50 \mathrm{~kg} / \mathrm{da})$ için en uygun ekim zamanının ekim ayı ortalarında olduğu belirlenmiştir. Yukarıdaki çalışmalar göz önüne alındığında çörekotunda tohum veriminin, yetiştirildiği ekolojik faktörler, toprak koşulları, kullanılan çeşitler, ekimlerin kışlık veya yazlık yapılması, kuru veya sulu koşullarda yetiştirme, gübreleme, ekim sıklığı gibi kültürel uygulamalardan önemli ölçüde etkilendiğini söyleyebiliriz.

Ülkemizde 2015 verilerine göre 4681 dekarlık alanda 425 ton çörekotu üretimi yapıldığı, buna karşılık aynı yıl 2898 ton çörek otu ithalatının gerçekleştiği bildirilmektedir (Temel ve ark., 2018). Oysaki ülkemizin iklimsel özellikleri ele alındığında ihtiyacımız olan çörekotunun tamamını üretebilme potansiyeline sahip olduğumuz sonucu ortaya çıkmaktadır. Yarı kurak iklim şartlarına sahip alanlarda sulama imkanı yoksa, yetiştirilebilecek bitki türü sayısı önemli ölçüde azalmakta ve ekimler mecburen kışlık olarak yapılmaktadır. Özellikle bu tip ekolojik bölgelerde suyu etkin kullanabilen bitkiler tercih edilmelidir. Bu bitkilerden bir tanesi de çörekotudur. Bölgemizde çörekotu tarımı yapılmamakla birlikte, yöre çiftçisi bitkiyi tanımamaktadır. Bu durumlar göz önünde bulundurularak, yağışa bağlı olarak çörekotunun bölgede yetişebilirliğini ve ekimin gecikmesiyle verimin nasıl etkileneceğini saptamak amacıyla bu çalışma yürütülmüştür.

\section{Materyal ve Yöntem}

Denemede Çameli çörekotu çeşidinin (Nigella sativa L.) tohumları materyal olarak kullanılmıştır. Deneme alanı toprakları orta derinlikte olup, az kireçli sınıfında, organik madde içerikleri orta düzeyde ve çözünür tuz içerikleri çok azdır (Çelik ve Akça, 2017). Çalışmanın yapıldığı aylara ait iklimsel özellikler Çizelge 1 'de verilmiştir.

Çizelge 1. Çalışmanın yürütüldüğü aylar ve uzun yıllar ortalamalarına ait yağış ve sıcaklık değerleri.

\begin{tabular}{lcccccccc}
\hline & \multicolumn{4}{c}{ Ortalama sıcaklık $\left({ }^{\circ} \mathbf{C}\right)$} & \multicolumn{3}{c}{ Yağış miktarı (mm) } \\
\cline { 2 - 9 } Aylar & $\mathbf{2 0 1 5}$ & $\mathbf{2 0 1 6}$ & $\mathbf{2 0 1 7}$ & Uzun yıllar & $\mathbf{2 0 1 5}$ & $\mathbf{2 0 1 6}$ & $\mathbf{2 0 1 7}$ & Uzun yıllar \\
\hline Kasım & 12.9 & 11.5 & 12.0 & 11.8 & 54.2 & 52.6 & 62.8 & 83.9 \\
Aralık & 8.0 & 4.0 & 9.0 & 6.5 & 40.2 & 135.8 & 43.6 & 112.3 \\
Ocak & 4.8 & 2.9 & 3.5 & 4.6 & 176.8 & 137.8 & 45.4 & 124.0 \\
Şubat & 6.5 & 9.8 & 5.6 & 5.8 & 160.1 & 80.8 & 0.8 & 103.9 \\
Mart & 9.6 & 11.6 & 11.0 & 10.0 & 117.1 & 28.0 & 89.9 & 78.9 \\
Nisan & 13.6 & 18.5 & 14.7 & 15.3 & 42.8 & 25.2 & 71.2 & 56.1 \\
Mayıs & 21.0 & 20.8 & 20.4 & 20.7 & 13.8 & 21.0 & 33.4 & 29.8 \\
Haziran & 26.4 & 27.8 & 27.7 & 27.0 & 1.8 & 17.4 & 14.2 & 8.4 \\
\hline
\end{tabular}

Denemenin ilk yılında aralık ve ocak ayında düşen yağışlar (sırasıyla 135.8 ve $137.8 \mathrm{~mm}$ ) uzun yıllar ortalamasından yüksek olurken, ikinci yılda aynı aylarda düşen yağışlar yaklaşık üç kat daha düşük olmuştur. Ancak, ikinci yıl mart (89.9 mm) ve nisan (71.2 $\mathrm{mm})$ aylarında uzun yıllar ortalamasından daha yüksek düşen yağışlar tohum verimine olumlu etki yapmıştır. İkinci yıl nisan ve mayıs aylarındaki yüksek yağışlar, hasatların 5- 6 gün daha geç yapılmasına neden olmuştur. Deneme yıllarında bitki yetiştiriciliği açısından sıcaklık değerleri olumsuz bir etki yaratmamakla birlikte en düşük ortalama sıcaklıklar her iki yılda da ocak ayında sırasıyla 2.9 ve $3.5{ }^{\circ} \mathrm{C}$ olarak gerçekleşmiştir. Uzun yıllar ortalamalarına göre en 
düşük sıcaklıklar aralık $\left(-7.2{ }^{\circ} \mathrm{C}\right)$, ocak $\left(-6.8^{\circ} \mathrm{C}\right)$ ve şubat aylarında $\left(-8.8^{\circ} \mathrm{C}\right)$ gerçekleşmektedir.

Bölge şartlarında uygun ekim zamanını belirlemek amacıyla, Adıyaman Üniversitesi Kahta Meslek Yüksekokulu uygulama alanında, 20152016 ve 2016-2017 yetiştirme sezonlarında, tesadüf bloklarında üç tekerrürlü olarak, 3 x $2.4 \mathrm{~m}$ ebatlarında parseller oluşturulmuş, $30 \mathrm{~cm}$ sıra aralığında $1.5 \mathrm{kgda}^{-1}$ tohumluk gelecek şekilde 4 farklı zamanda, kasım, aralık, ocak ve şubat aylarında, yağış durumuna bağlı olarak ekimler elle yapılmıştır. Her ekimden önce, saf etkili madde üzerinden $5 \mathrm{kgda}^{-1}$ fosfor gelecek şekilde $\mathrm{Di}$ Amonium Fosfat gübresi taban gübrelemesi ve çiçeklenmeden önce azot ihtiyacını karşılamak üzere geri kalan Amonium Nitrat yağışlardan önce üst gübre (4 kg/da saf azot) olarak verilmiştir. Deneme alanındaki yabancı otlar çapayla deneme alanından uzaklaştırılmıştır. Alınan gözlemler ve yapılan işlemler Çizelge 2'de verilmiştir.

Çizelge 2. Yarı kurak koşullarda ekim zamanlarının çörekotunda (Nigella sativa L.) tohum verimine etkisine ait alınan gözlemler ve yapılan işlemler.

\begin{tabular}{|c|c|c|c|c|c|c|}
\hline \multicolumn{2}{|c|}{ Ekim zamanı } & \multirow{2}{*}{$\frac{\text { Ekim tarihi }}{25.11 .2015}$} & \multirow{2}{*}{$\frac{\text { ilk çıkış }}{18.12 .2015}$} & \multirow{2}{*}{$\begin{array}{c}\text { Üst gübre } \\
09.02 .2016\end{array}$} & \multirow{2}{*}{$\begin{array}{c}\text { Çiçeklenme } \\
15.04 .2016\end{array}$} & \multirow{2}{*}{$\begin{array}{c}\text { Hasat } \\
26.05 .2016\end{array}$} \\
\hline Kasım & 1.YII & & & & & \\
\hline & 2.YII & 19.11.2016 & 19.12.2016 & 25.01.2017 & 17.04.2017 & 02.06 .2017 \\
\hline \multirow[t]{2}{*}{ Aralık } & 1.Yıl & 25.12.2015 & 02.02 .2016 & 09.03.2016 & 22.04.2016 & 01.06 .2016 \\
\hline & 2.Yıl & 19.12.2016 & 29.01.2017 & 01.03.2017 & 23.04.2017 & 08.06.2017 \\
\hline \multirow[t]{2}{*}{ Ocak } & 1.Yıl & 05.01 .2016 & 25.02 .2016 & 11.04.2016 & 26.04.2016 & 06.06 .2016 \\
\hline & 2.Y YI & 18.01.2017 & 23.02.2017 & 23.03.2017 & 25.04.2017 & 10.06.2017 \\
\hline Şubat & 1.Yıl & 19.02 .2016 & 03.03 .2016 & 11.04 .2016 & 01.05 .2016 & 12.06 .2016 \\
\hline
\end{tabular}

Bitkilerin su ihtiyacı yağışla karşılanmış, sulama yapılmamıştır. Hasada gelen bitkilerden, bitkisel özellikleri belirlemek amacıyla, parselleri temsil eden 20 bitki tesadüfen seçilmiştir. Parsellerde kenar tesirleri çıkartıldıktan sonra (2.2 x 1.6 m'lik alanda) hasatlar yapılmış ve parsellerden elde edilen tohum verimleri dekara çevrilmiştir. Elde edilen verilerin istatistiksel analizleri Mstat-C paket programında yapılmış olup, oluşan guruplar EGF'ye (En Güvenilir Fark) göre yorumlanmıştır.

\section{Bulgular ve Tartışma Bitki boyu}

Yarı kurak koşullarda, farklı ekim zamanlarında yetiştirilen çörekotunda bitkisel özelliklere ait, birinci yılda alınan veriler ikinci yıldan daha yüksek olmuştur. Denemenin kurulduğu her iki yılın ve iki yıl ortalamalarına ait değerler Çizelge 3'te verilmiştir. En yüksek bitki boyu değerleri (34.57-44.93 cm) her iki yılda da ilk ekimlerden, en düşük bitki boyu değerleri ise $(24.13-26.07 \mathrm{~cm})$ son ekimlerin yapıldığı şubat ayında belirlenmiştir. Bitki boyu değerleri incelendiğinde, bütün ekim zamanlarında, ikinci yıldan elde edilen verilerin, ilk yıldan daha yüksek olduğu saptanmıştır. Bu durumun en önemli nedenlerinden birisinin, ikinci yılda, özellikle bahar yağışlarının yüksek olmasından kaynaklanmıştır. İlk iki ekim zamanından elde ettiğimiz bitki boyu değerleri, Tunçtürk ve ark. (2005), Kızıl ve ark. (2008) Agha ve ark. (2010), Rabbani ve ark. (2011)'larının bildirdikleri değerlerle uyum halindeyken, son iki ekim zamanında tespit ettiğimiz değerler daha düşük çıkmıştır. Yapılan bazı çalışmalarda ise bitki boyunun $40.78-89.60 \mathrm{~cm}$ arasında değiştiği bildirilmektedir (El-Mekawy,

2012; Haq ve ark., 2015; Kılıç ve Arabacı, 2016;
Beyzi, 2018). Bildirilen bu değerler elde ettiğimiz verilerden oldukça yüksektir. Bu durum, muhtemelen çalışmaların farklı ekolojilerde yapılması, uygulanan kültürel işlemler, ekim zamanları (yazlık- kışlık) ve genotipik farklılıklardan kaynaklanmıştır.

\section{Dal sayısı}

Yarı kurak koşullarda, farklı ekim zamanlarında, çalışmanın yürütüldüğü yıllarda saptanan dal sayısı değerleri Çizelge 3'te verilmiştir. Bitki başına düşen en yüksek dal sayısı, ilk yıl birinci ekim zamanında 5.30 adet/bitki olarak saptanırken, en düşük dal sayısı değeri her iki yılda da şubat ayında yapılan ekimlerde 2.67 adet/bitki olarak saptanmıştır. Her iki yılda da ekimin gecikmesiyle bitki başına düşen dal sayılarında azalmaların olduğu tespit edilmiştir. Yarı kurak iklim şartlarında yapılan bazı çalışmalarda dal sayısının 2.44-6.50 adet/bitki arasında olduğu bildirilmektedir (Özel ve ark., 2002; Kızıl ve ark., 2008). Bulgularımız bildirilen bu değerler arasında olup, yapılan bir çok çalışmada bulgularımızdan daha yüksek değerler bildirilmiştir (Tunçtürk ve ark., 2005; Agha ve ark., 2010; Haq ve ark., 2015; Kılıç ve Arabacı, 2016). Ekolojik faktörler bitki büyüme ve gelişimi açısından oldukça önemlidir. Bununla birlikte uygulanan kültürel önlemlerin dal sayısı üzerine etkisi göz önünde tutulmalıdır.

\section{Kapsül sayısı}

Çalışmada en yüksek kapsül sayıları ilk ekim zamanı olan kasım ayında belirlenmiştir. İlk ekim zamanı ile son ekim zamanı arasında bitki başına düşen kapsül sayılarında yaklaşık yarı yarıya kadar 
bir fark oluşmuştur. En yüksek kapsül sayısı (11.47 adet/bitki) ikinci yıl kasım ayında yapılan ekimlerde saptanırken, en düşük kapsül sayısı (6.08 adet/bitki), en son ekim zamanı olan şubat ayında birinci yıl yapılan ekimlerde belirlenmiştir. Dal sayısında olduğu gibi ekim zamanının gecikmesiyle kapsül sayılarında, kademeli olarak belirgin azalmalar oluştur. Tüm ekim zamanlarında tespit ettiğimiz değerler Özel ve ark. (2002)'nın bildirdikleri değerlerden yüksek olurken, Tunçtürk ve ark. (2005), Kızıl ve ark. (2008), Agha ve ark. (2010), Haq ve ark. 2015, Kılıç ve Arabacı, (2016)'nın bildirdikleri değerlerden düşük çıkmıştır.

Çizelge 3. Yarı kurak koşullarda, farklı ekim zamanlarında yetiştirilen çörekotuna (Nigella sativa L.) ait bazı bitkisel özellikler.

\begin{tabular}{lccccccccc}
\hline \multirow{2}{*}{ Ekim zamanı } & \multicolumn{3}{c}{$\begin{array}{c}\text { Bitki boyu } \\
\text { (cm) }\end{array}$} & \multicolumn{3}{c}{$\begin{array}{c}\text { Dal sayısı } \\
\text { (adet bitki }^{-1} \text { ) }\end{array}$} & \multicolumn{3}{c}{ Kapsül sayısı (adet bitki ${ }^{-1}$ ) } \\
\cline { 2 - 10 } & $\mathbf{2 0 1 6}$ & $\mathbf{2 0 1 7}$ & Ort. & $\mathbf{2 0 1 6}$ & $\mathbf{2 0 1 7}$ & Ort. & $\mathbf{2 0 1 6}$ & $\mathbf{2 0 1 7}$ & Ort. \\
\hline Kasım & $34.57 \mathrm{c}$ & $44.93 \mathrm{a}$ & 39.75 & $4.38 \mathrm{~b}$ & $5.30 \mathrm{a}$ & 4.84 & $10.62 \mathrm{a}$ & $11.47 \mathrm{a}$ & 11.04 \\
Aralık & $28.47 \mathrm{~d}$ & $39.30 \mathrm{~b}$ & 33.88 & $3.90 \mathrm{c}$ & $4.20 \mathrm{bc}$ & 4.05 & $8.84 \mathrm{~b}$ & $7.87 \mathrm{bc}$ & 8.35 \\
Ocak & $26.67 \mathrm{~d}$ & $33.80 \mathrm{c}$ & 30.23 & $3.20 \mathrm{~d}$ & $3.47 \mathrm{~d}$ & 3.33 & $7.80 \mathrm{c}$ & $6.33 \mathrm{~d}$ & 7.07 \\
Şubat & $24.13 \mathrm{e}$ & $26.07 \mathrm{de}$ & 25.10 & $2.67 \mathrm{e}$ & $2.67 \mathrm{e}$ & 2.67 & $6.08 \mathrm{~d}$ & $6.17 \mathrm{~d}$ & 6.13 \\
Yıl Ort. & 12.70 & 36.03 & & 3.54 & 3.91 & & 8.34 & 7.96 & \\
EGF(\%1)* & & 2.47 (int) & & & 0.42 & & & 0.99 \\
\hline
\end{tabular}

*yıl x aylar interaksiyonu \%1 düzeyinde önemli.

\section{Kapsülde tohum sayısı}

Yarı kurak koşullarda, farklı ekim zamanlarında yetiştirilen çörekotuna ait kapsüldeki tohum sayısına ilişkin saptanan değerler Çizelge 4'te verilmiştir. Kapsüldeki en yüksek tohum değeri ikinci yıl, kasım ayı ekimlerinde 66.13 adet/kapsül olarak belirlenmiştir. En düşük değer ise ilk yıl, şubat ayı ekimlerinde 51.97 adet/kapsül olarak saptanmıştır. Kasım ve aralık aylarında yapılan ekimlerden elde ettiğimiz kapsüldeki tohum sayıları Özel ve ark. (2002)'nın bulgularından yüksek, Kızıl ve ark. (2008) ile Agha ve ark. (2010)'nın bildirdikleri değerler arasında, bir çok araştırıcının bildirdikleri değerlerden ise daha düşük çıkmıştır (Tunçtürk ve ark., 2005; Agha ve ark., 2010; Haq ve ark., 2015; Kılıç ve Arabacı, 2016; Beyzi, 2018). Ocak ve şubat aylarında yapılan ekimlerde kapsüldeki tohum sayıları düşük çıkmıştır. Ekim ile hasat arasındaki sürenin kısalmasının kapsüldeki tohum sayısının düşmesine neden olabileceği düşünülmektedir.

\section{Bin tohum ağırlığı}

Bin tohum ağırlıkları bakımından, ekim zamanları arasında istatistiksel anlamda iki farklı grubun oluştuğu Çizelge 4'te görülmektedir. Buna göre istatistiksel anlamda ilk iki ekim zamanından elde edilen sonuçlar bir grup, son iki ekim zamanından elde edilen sonuçlar da bir gruba dahil olmuştur. En yüksek bin tohum ağırlıkları (2.642.62 g) yine ilk ekim zamanında, en düşük bin tohum ağırlıkları (2.51-2.52 g) da son ekim zamanında belirlenmiştir. Yapılan literatür çalışmasında çörekotunda bin tohum ağırlığının 1.48-2.73 g arasında değiştiği görülmüştür (Özel ve ark., 2002; Tunçtürk ve ark., 2005; Kızıl ve ark.,
2008; Haq ve ark., 2015; Kılıç ve Arabacı, 2016; Beyzi, 2018). Sharangi ve ark. (2014) kişniş bitkisinde ekimin gecikmesi ile birlikte sıcaklığın artmasına bağı olarak, bitkilerin hızlı bir şekilde vejetatif dönemini geçirdiği bu nedenle bin tohum ağırlığı ve bitki başına düşen şemsiye sayısında azalmaların olduğunu bildirmektedirler. Tüm ekim zamanlarında saptadığımız bin tohum ağırlığına ait değerler bildirilen değerlerin üst sınırına çok yakındır. Çalışmamızda, her iki yılda da ekimin gecikmesi ile birlikte bin tohum ağırlığının düştüğü tespit edilmiştir.

\section{Tohum verimi}

Yarı kurak koşullarda, farklı ekim zamanlarında yetiştirilen çörekotundan elde edilen tohum verimlerine ilişkin değerler Çizelge 4'te verilmiştir. Çalışmada incelenen tüm özelliklerde olduğu gibi, en yüksek tohum verimleri ilk yıl 46.77 $\mathrm{kg} / \mathrm{da}$, ikinci yıl $49.11 \mathrm{~kg} / \mathrm{da}$ olarak kasım ayında yapılan ekimlerden alınmıştır. En son ekim zamanı olan şubat ayında ise tohum verimleri sırasıyla $31.49 \mathrm{~kg} / \mathrm{da}$ ve $32.05 \mathrm{~kg} / \mathrm{da}$ 'a kadar gerilemiştir. Çörekotu ekim zamanı ile yapılan çalışmalarda da ekim zamanının gecikmesiyle birlikte tohum verimlerinin azaldığı bildirilmektedir (Özel ve ark., 2002; Kızıl ve ark., 2008; Haq ve ark., 2015; Kılıç ve Arabacı, 2016). Çörekotunda tohum veriminin 28.5 $\mathrm{kg} /$ da'dan, $146.00 \mathrm{~kg} / \mathrm{da}$ 'a kadar ulaşabildiği ile ilgili çalışmalar mevcuttur (Özel ve ark., 2002; Tunçtürk ve ark., 2005; Kızıl ve ark., 2008; Agha ve ark., 2010; Kılıç ve Arabacı, 2016; Beyzi, 2018). Tohum verimindeki bu farklılıklar muhtemelen, çalışmaların yürütüldüğü ekolojiler, özellikle ekim zamanları (kışlık- yazlık), kültürel koşullar, gübreleme, çalışmaların tescilli çeşit veya yerel 
popülasyonlar ile yapılması gibi bazı nedenlerden

ileri gelebilmektedir.

Çizelge 4. Yarı kurak koşullarda, farklı ekim zamanlarında yetiştirilen çörekotuna (Nigella sativa L.) ait kapsüldeki tohum, bin tohum ağırlığı ve tohum verimine ilişkin elde edilen veriler.

\begin{tabular}{|c|c|c|c|c|c|c|c|c|c|}
\hline \multirow[t]{2}{*}{ Ekim zamanı } & \multicolumn{3}{|c|}{$\begin{array}{l}\text { Kapsülde tohum sayısı (adet } \\
\text { kapsül }^{-1} \text { ) }\end{array}$} & \multicolumn{3}{|c|}{$\begin{array}{c}\text { Bin tohum ağırlığı } \\
\text { (g) }\end{array}$} & \multicolumn{3}{|c|}{$\begin{array}{c}\text { Tohum verimi } \\
\left(\mathrm{kg} \mathrm{da}^{-1}\right)\end{array}$} \\
\hline & 2016 & 2017 & Ort. & 2016 & 2017 & Ort. & 2016 & 2017 & Ort. \\
\hline Kasım & $61.70 b c$ & $66.13 a$ & 63.92 & $2.64 a$ & $2.62 a$ & 2.63 & $46.77 b$ & $49.11 a$ & 47.94 \\
\hline Aralık & $63.30 \mathrm{~b}$ & $63.67 a b$ & 63.48 & 2.59ab & $2.58 \mathrm{ab}$ & 2.59 & $39.42 c$ & $39.73 c$ & 39.58 \\
\hline Ocak & $53.37 d$ & $60.14 b$ & 57.75 & $2.54 b c$ & $2.54 b c$ & 2.54 & $33.27 d$ & $33.07 d$ & 33.17 \\
\hline Şubat & $51.97 d$ & $54.23 d$ & 55.60 & $2.50 c$ & $2.52 \mathrm{bc}$ & 2.51 & $31.49 \mathrm{e}$ & $32.05 \mathrm{de}$ & 31.77 \\
\hline Yıl Ort. & 57.59 & 61.04 & & 2.57 & 2.57 & & 37.74 & 38.49 & \\
\hline EGF(\%1)* & & 2.63 & & & 0.08 & & & 1.57 & \\
\hline
\end{tabular}

*yll x aylar interaksiyonu \%1 düzeyinde önemli.

\section{Sonuç ve Öneriler}

Yarı kurak koşullarda, farklı ekim zamanlarında ve yağışa bağlı olarak yürütülen bu çalışmada, çörekotunda kasım ayı ekimlerinin gerek bitkisel özellikler gerekse tohum verimi açısından en uygun ekim zamanı olduğu sonucuna varılmıştır. Yağışa dayalı şekilde gerçekleştirilecek olan ekimlerin zamanında yapılabilmesi için de sonbahar yağışlarının erken bir dönemde alınmasının olumlu etkisinin olacağı düşünülmektedir. Ekim zamanı geciktikçe verimde azalmaların olduğu tespit edilmiştir. Bu nedenle ilk düşen sonbahar yağışlarından hemen sonra toprak hazırlığı ve ekimlerin en kısa sürede yapılması gerekmektedir. Özellikle erken ilkbaharda yapılan ekimler ile hasat zamanı arasındaki sürenin kısalması ve yarı kurak koşullarda sıcaklıkların ani artışıla birlikte bitkilerin erken olgunlaşmaya başlaması, bitki boyunu, dal sayısını buna bağlı olarak kapsül sayısını, kapsüldeki tohum sayısını ve dolayısıyla tohum veriminin düşmesine neden olmaktadır. Bu durumlar göz önünde bulundurularak, yarı kurak iklim şartlarına sahip alanlarda kışlık ekimin, yazlık ekimlere göre daha yüksek verim verdiği, yazlık ekim yapılacaksa bile mümkün olduğu kadar erken ilkbaharda ekimlerin yapılması gerektiği sonucuna varılmıştır.

\section{Kaynaklar}

Agha, Q., Ahmad, S., Islam, M., Gill, A., Athar, M. 2010. Growth and production potential of five medicinal crops in highlands of Balochistan. Pakistan Journal of Medicinal Plants Research, 4(20): 2159- 2163.

Baydar, H. 2013. Tıbbi ve Aromatik Bitkiler Bilimi ve Teknolojisi (Genişletilmiş 4. Baskı) Süleyman Demirel Üniversitesi Yayın No:51, Isparta, $303 \mathrm{~s}$.

Beyzi, E. 2018. Çörek Otu Bitkisinin (Nigella sativa L.) Kayseri ekolojik koşullarında verim ve kalite özelliklerinin belirlenmesi. Avrupa Bilim ve Teknoloji Dergisi, 14: 245- 248.
D'Antuono, L.F., Moretti, A. and Lovato, A.F.S. 2002. Seed yield, yield components, oil Content and essential oil content and composition of Nigella sativa L. and Nigella damascena L. Industrial Crops and Products, 15: 59- 69.

Çelik, A., Akça, E. 2017. Adıyaman'da Eğimli Akarsu Seki Topraklarının Sürdürülebilir Kullanımı için Öneriler, Yüzüncü Yıl Üniversitesi Tarla Bilimleri Dergisi, 27(1): 139- 150.

El-Mekawy, M.A.M. 2012. Growth and Yield of Niglla sativa L. Plant Influenced by Sowing Date and Irrigation Treatments AmericanEurasian J. Agric. \& Environ. Sci., 12 (4): 499505.

Haq, M.Z., Hossain, M.M., Haque, M.M., Das, M.R., Huda, M.S. 2015. Blossoming characteristics in black cumin genotypes in relation seed yield influenced by sowing time. American Journal of Plant Sciences, 6: 1167- 1183.

Kaleem, S., Hassan, F.U., Mahmood, I., Ahmad, M., Ullah, R., Ahmad, M. 2011. Response of sunflower to environmental disparity. Nature and Science, 9: 73-81.

Kılıç, C., Arabacı, O. 2016. Çörek otu (Nigella sativa L.)'nda farklı ekim zamanı ve tohumluk miktarının verim ve kaliteye etkisi. Adnan Menderes Üniversitesi Ziraat Fakültesi Dergisi, 13(2) : 49 - 56.

Kızıl, S., Kırıcı, S., Çakmak, Ö., Khawar, K.M. 2008. Effects of sowing periods and $P$ application rates on yield and oil composition of black cumin (Nigella sativa L.). Journal of Food, Agriculture \& Environment, 6(2) : 242- 246.

Moosavi, S.G. 2014. Fennel Morphological Traits and Yield as Affected by Sowing Date and Plant Density. Advance in Agriculture and Biology, 2, 45-49. 
Özel, A., Demirbilek, T., Güler, İ. 2002. Harran Ovası kuru koşullarında farklı ekim zamanlarının çörekotu türleri (Nigella spp.)'nin verim ve bazı tarımsal karakterlerine etkisi. Harran Üniversitesi Ziraat Fakültesi Dergisi, 6(3-4): 81-90.

Rabbani, M.A., Ghafoor, A., Masood, M.S. 2011. Narc-Kalonjı: an early maturing and high yielding variety of Nigella sativa released for cultivation in Pakistan. Pakistan Journal of Botany, 43: 191-195 (Special Issue).

Sharangi, A.B., Roychowdhury, A. 2014. Phenology and yield of coriander (Coriandrum sativum L.) at different sowing dates. Journal of Plant Sciences, 9: 32-42.

Siddiqui, A.A. and Sharma, P.K.R. 1996. Clinical importance of Nigella sativa Linn. Hamdard Medicus, 39: 38-42.

Tembhurne, S.V., Feroz, S., More, B. H., Sakarkar, D.M. 2014. A review on therapeutic potential of Nigella sativa (kalonji) seeds. Journal of Medicinal Plants Research, 8 (3): 167- 177.

Temel, M., Tınmaz, A.B., Öztürk, M., Gündüz, O. 2018. Dünyada ve Türkiye'de Tıbbi-Aromatik Bitkilerin Üretimi ve Ticareti. Kahramanmaraş Sütçü İmam Üniversitesi, Tarım ve Doğa Dergisi (Özel Sayı), 21: 198214.

Tunçtürk, M., Ekin, Z., Türközü, D. 2005. Response of black cumin (Nigella sativa L.)to different seed rates growth, yield components and essential oil content. Journal of Agronomy, 4(3): 216- 219. 